\title{
The Role of Febrile Neutropenia Guideline's Implementation on Mortality Rate in Dharmais Hospital- National Cancer Center
}

\author{
Dody Ranuhardy
}

Department of Hematology and Medical Oncology, Dharmais Hospital-National Cancer Center, Jakarta, Indonesia

\section{ARTICLE INFO}

\section{Article history:}

Received : 09 August 2018

Reviewed: 29 August 2018

Accepted : 09 November 2018

\section{Keywords:}

Compromised immune isolation room, Guidelines of febrile neutropenia, Mortality rate
*Corresponding author:

Dody Ranuhardy

Department of Hematology and

Medical Oncology, Dharmais

Hospital-National Cancer Center.

Email: ranuhardy_rskd@yahoo.com

\begin{abstract}
A BSTRACT
Introduction: Febrile neutropenia have a high morbidity and mortality impact for the patient. The mortality rate of febrile neutropenia in 2002 was $38.8 \%$, while it was $27.3 \%$ in 2009 . The difference in mortality rates could be caused by several factors such as availability of the Neutropenic Fever Management Guidelines in 2006, in addition to infrastructure, human resources and equipment. This study aims to determine the role of guideline availibility and other factors to cancer mortality rate in the immunocompromised isolation room of Dharmais Hospital.
\end{abstract}

Methods: This study was a cross-sectional retrospective study which investigate mortality rates and compare with adherence to febrile neutropenia guidelines for the period 2008-2012. Data were taken from the patient's medical record file, and then analysed using univariate and bivariate analysis.

Results: The mortality rate in the period $2008-2012$ was $20.7 \%$. The correlation between age, sex, and degree of risk factor on mortality was not significantly different $(p=0,409, p=0,404$, and $p=0,324)$. The proportion of deaths was higher in patients borne by third parties $(26.8 \%)$ than in the case of personal $(10 \%)$ although not statistically significant $(p=0,065)$. From the three types of adherence, only one had a significant effect of adherence to treatment flow $(p=0,033)$.

Conclusions: The availibility of management guideline can reduce mortality rate of febrile neutropenia even though from the three types of adherence, only one had a significant effect of adherence to treatment flow $(p=0,033)$.

\section{INTRODUCTION}

Febrile neutropenia (FN) is defined as an oral temperature $>38.5^{\circ} \mathrm{C}$ or two consecutive readings of $>38.0^{\circ} \mathrm{C}$ for 2 hours and an absolute neutrophil count $<0.5 \times 10^{9} /$ l, or expected to fall below $0.5 \times 10^{9} /$ l (1). Febrile neutropenia is a common complication in cancer patients who are undergoing treatment and may have impacts on morbidity and mortality (1-3). Rates of neutropenia who receive chemotherapy for solid tumors was $5-10 \%$, whereas patients with hematological malignancy have rates more than $20 \%$, and incidence in patients who have bone marrow transplant was 70$100 \%$ (4). Dharmais Hospital-National Cancer Center, Jakarta recorded febrile neutropenia mortality rate in 1999,2000 , and 2002 in was $12.5 \%, 22.5 \%$, and $38.8 \%$, respectively. While in Indonesia, there is no national data about the magnitude of neutropenic febrile mortality rate (5).

Mortality rate due to neutropenic fever is increasing, except in 2009, there was a considerable decrease in mortality rate. From $38.8 \%$ in 2002 became $27.3 \%$ in 2009. The difference in mortality rate may be due to several factors, including the availability of guideline on neutropenic fever in 2006, in addition to infrastructure, human resources, equipment, and systems (6).

The current management of neutropenia includes modification of chemotherapy doses, prolonged dose interval, and primary prophylaxis with recombinant GCFS (7). Guidelines of FN in cancer patients itself aims to achieve the same perception and understanding of neutropenic fever management in Indonesia, more 
effective, safe, efficient and rational use of antibiotics, avoid accelerated antibiotic resistance, and obtain empirical data that can be continuously updated (6).

The more detailed clarification and evaluation about guidelines of febrile neutropenia management in isolation room, Dharmais Hospital-National Cancer Center which was enforced since 2006 is required. This evaluation should have an outcome in mortality rate and factors that influence. The aim of this study is to obtain the role of management guideline availability and other factors in mortality rate of neutropenic fever patients in Dharmais Hospital-National Cancer Center in the year 2008-2012.

\section{METHODS}

This was a retrospective, cross-sectional study using secondary data from Dharmais Hospital-National Cancer Center in the period between 2008-2012. The data were obtained from medical records of patients who were diagnosed with febrile neutropenia in Dharmais Hospital-National Cancer Center.

Inclusion criteria for subjects were being treated in isolation room; having fever (axillary temperature $\geq 38^{\circ} \mathrm{C}$ at two measurements within an hour or more for solid tumor, $\geq 37.5^{\circ} \mathrm{C}$ for hematologic cancer, or $\geq 38.3^{\circ} \mathrm{C}$ at first measurement and no signs of non-infection); and being diagnosed with neutropenia (neutrophils $<500$ cells $/ \mathrm{mm}^{3}$ or $<1000$ cells $/ \mathrm{mm}^{3}$ with downward trend towards 500 cells $/ \mathrm{mm}^{3}$ in next two days). While exclusion criteria of this study were incomplete data, both related to recording in medical record or loss of data in the medical record. Data of patients that met the inclusion criteria and avoid the exclusion criteria were collected and then tabulated. The degree of risk factor was based on Guideline of FN Management.

The subjects were then categorized in the three categories, low risk: solid tumors, using conventional chemotherapy, no comorbidity, brief neutropenia $(\leq 3$ days), no signs of severe infection, no signs of sepsis or shock; moderate risk: solid tumors or hematological malignancies, using intensive chemotherapy with/without comorbidity, neutropenia was lasting 3-7 days, with/without the signs of clinical infection, with/without the signs os sepsis or shock; and high risk: hematological malignancy, using agresive chemotherapy/Peripheral Blood Stem Cell Transplant (PBSCT)/Bone Marrow Transplantion (BMT), with/without comorbidity, long-term neutropenia ( $\geq 7$ days), with/without the sign of clinical infection, and with/without the signs of sepsis of shock.

The data of compliance was scored to perform statistical analysis. The indepedent numerical variables were tested using 2 mean differences, while independent categorical variable were tested using Chi square, Fischer's Exact Test, and Pearson Chi Square. Multivariate analysis were used to find correlation between all of independent variables towards dependent variable if there were more than one variable that statistically significant.

The variables seen in this study were medication flow adherence, medication principal adherence, initiation or termination of medication, age, gender, degree of neutropenic fever, and cost capability. All of these factors were corelated with mortality rate.

\section{RESULTS}

The amount of $\mathrm{FN}$ cases which were obtained through patient registration in isolation room throughout 2008-2012 were 212. Data which did not meet fever criteria were 43 cases, neutropenia criteria were 2 cases, and incomplete data were 56 cases. So total data that could be processed was 111 cases.

\section{Characteristics of Subjects Demography}

The mean of age was 37.8 years (SD 13.8). The youngest was 13 and the oldest was 70 . Then subjects were divided into two groups. Younger patients (13-38) were 58 patients $(52.3 \%)$ and the rest $(47.7 \%)$ were over 38 years old. In this study, men $(57.7 \%)$ are more likely to have neutropenic fever than women (42.3\%). Neutropenic fever patients which have the third party as person in charge were $64 \%$. The guarantors as the third party include Jaminan Perusahaan, Asuransi, Askes, Jamkesda, and Jamkesmas. Based on the degree of risk factor, high risk became the most commonly obtained.

\section{Characteristics of Physician Compliance on Guideline of Neutropenic Fever Management}

Physician compliance of management algorithm was based on Guideline of FN Management that includes 5 parameters: 1 . empirical antibiotics utilization at the start of treatment according to degree of risk; 2 . replacement of the type of antibiotic in case of worsening after 72 hours; 3. examination for reevaluation after 72 hours; 4 . administration of antifungal drugs according to degree of risk; 5 . termination antibiotic/anti-fungal treatment according to degree of risk.

While parameters of physician compliance on treatment principal are: 1 . start antibiotic as soon as possible; 2 . empirical according to guideline; 3 . utilization of bactericidal antibiotic, not bacteriostatic, and; 4. utilization of broad-spectrum antibiotic. Both groups of parameter were scored, 0 (zero) if it is not appropriate and 5 (five) if it is most appropriate. Categorized as obedient if the total score is $\geq 15$. 
Table 1. Relationship between adherence to Guideline of neutropenic fever management and mortality rate

\begin{tabular}{|c|c|c|c|}
\hline Variable of compliance & $\begin{array}{c}\text { Number of life } \\
\mathrm{N}(\%) \\
\end{array}$ & $\begin{array}{c}\text { Number of death } \\
\text { N (\%) }\end{array}$ & $P$ value \\
\hline \multicolumn{4}{|l|}{ Management algorithm } \\
\hline Obedient & $71(84,5)$ & $13(15,5)$ & $0,033^{*}$ \\
\hline Disobedient & $17(63,0)$ & $10(37,0)$ & \\
\hline \multicolumn{4}{|l|}{ Treatment principal } \\
\hline Obedient & $70(77,8)$ & $20(22,2)$ & $0,556 * *$ \\
\hline Disobedient & $18(85,7)$ & $3(14,3)$ & \\
\hline \multicolumn{4}{|l|}{ Starting treatment } \\
\hline Obedient & $70(77,8)$ & $20(22,2)$ & $0,556^{*}$ \\
\hline Disobedient & $18(85,7)$ & $3(14,3)$ & \\
\hline
\end{tabular}

${ }^{*}$ Chi-Square Test

**Fisher's Exact Test

Table 2. Relationship between other factors and mortality rate

\begin{tabular}{|c|c|c|c|}
\hline Variable & $\begin{array}{c}\text { Number of life } \\
\text { N (\%) }\end{array}$ & $\begin{array}{c}\text { Number of death } \\
\mathbf{N}(\%)\end{array}$ & P value \\
\hline \multicolumn{4}{|l|}{ Group of age: } \\
\hline 13-38 years old & $48(82,8)$ & $10(17,2)$ & \multirow[t]{2}{*}{$0,477^{*}$} \\
\hline$>38$ years old & $40(75,5)$ & $13(24,5)$ & \\
\hline \multicolumn{4}{|l|}{ Gender: } \\
\hline Men & $35(74,5)$ & $12(25,5)$ & \multirow[t]{2}{*}{$0,404^{*}$} \\
\hline Women & $53(82,8)$ & $11(17,2)$ & \\
\hline \multicolumn{4}{|l|}{ Person in charge } \\
\hline Personal & $36(90,0)$ & $4(10,0)$ & \multirow[t]{2}{*}{$0,065^{*}$} \\
\hline Third party & $52(73,2)$ & $19(26,8)$ & \\
\hline \multicolumn{4}{|c|}{ The degree of risk factor } \\
\hline Low & $5(100)$ & $0(0)$ & \multirow{3}{*}{$0,324 * *$} \\
\hline Moderate & $3(100)$ & $0(0)$ & \\
\hline High & $80(77,7)$ & $23(22,3)$ & \\
\hline
\end{tabular}

${ }^{*}$ Chi Square Test

**Fisher's Exact Test

The Doctors who adhere to the management algorithm (67.6\%) were more than those who do not (32.4\%). As well as management algorithm, doctors who adhere to treatment principal (81.1\%) were more than those who do not (18.9\%) (Table 2).

For the starting treatment criteria, the parameter used started at $<24$ hours are obedient and started at $>24$ hours are disobedient. Doctors who adhere to starting treatment $(81.1 \%)$ were higher than those who do not $(18.9 \%)$.

\section{Number of Cases}

Life cases (79.3\%) were more than mortality cases (20.7\%). This data showed that the number of FN related death cases in Dharmais Hospital-National Cancer Center at the period 2008-2012 was $20.7 \%$.

\section{Data Analysis}

This study found that adherence to management algorithm had a significant effect on mortality rate compared to disobedience. Mortality rate in obedient cases was $15.5 \%$ and disobedient was $37 \%(p=0,033)$. While the adherence to treatment principle and starting of treatment had no significant effect on mortality rate of neutropenic fever $(p=0,556$ and $p=0,556$, respectively) (Table 1).

Other factors that were seen in this study were age, gender, a person in charge, and degree of risk. All of these factors had no significant effect in neutropenic fever mortality rate $(p>0,05)$ (Table 2 ).

\section{DISCUSSION}

Data that could be analyzed from isolation room during the period of 2008-2012 were 111 data (52.35\%). Data were excluded because of avoidance of the criteria for neutropenic fever (21.2\%) and data incompleteness (26.45\%). This problem occurred due to medical record documents that in the 10 years period were not used anymore, considered to be inactive and would be transferred to the warehouse. In addition, the neutropenic fever diagnosis was rarely written as a 
diagnosis, both primary or secondary diagnose in the medical record.

Clinical guidelines are essential if problems are frequent or costly. There are wide variations in management practices with sufficient scientific evidence for optimal implementation. Guidelines of neutropenic fever management was qualified as a good clinical guide and can be implemented because it met most of prescribed requirements, i.e. certified fields which are clinically relevant; based on randomized controlled trials; the intended target was very clear, easy to understand, supported by resources, and as a tool for clinical staffs to provide the best service to the patient. The three items that were not-fulfilled have been measured, namely the improvements, continous update, and reward system (8).

The mortality rate in isolation room at the observation period after the availability of neutropenic fever guideline was decreased (20.7\%) compared to the previous data in 2000 (22.5\%) and 2002 (38.8\%). However, these numbers are still higher compared with Europe and America. The mortality rate becomes very important related to service quality. Based on the Indonesian Ministry of Health, one of the indicators in hospital service quality assessment is Gross Death Rate (GDR). GDR is the total count of mortality rate that occurs both before and after 48 hours compared to 1000 outpatients (6).

Although the mortality rate was higher in older age and women, statistically age and gender differences did not significantly correlates to mortality rate $(p=0,409$ and $p=0,404)$. Its relation to physical and emotional condition still needs to be proven (9). Age, gender, and type of chemotherapy actually are marginally significant factors.

The proportion of death cases was higher in patients who bear a third party (26.8\%) than personal (10\%), although the difference is not statistically significant $(p=0,065)$. This is caused by a third party that did not fully warrant the cost. They used cost-sharing system, so patients with financial constraints would face treatment problems, such as the selection of antibiotics and other unaccounted examinations.

In terms of degree of risk factors, the mortality rate was higher in high-risk group $(22.3 \%)$ compared to moderate $(0 \%)$ or low-risk group $(0 \%)$, although the comparison is not statistically significant. It could be understood because most cases which were treated in isolation room were acute leukaemia (90\%). High frequency of mortality rate in high-risk group may be due to the availability of some equipment, such as sterile rooms, human resources, and better service system including the availability of neutropenic fever guideline.

This study demonstrated that adherence to management algorithm (33.3\%) has a very significant effect on mortality rate $(p=14.7 \%)$ compared to disobedience $(p=0,043)$. The disobedience of doctors to the principle of treatment that caused mortality rate by $14.3 \%$ was due to delays in empiric antibiotics, nonbactericidal empirical or narrow-spectrum antibiotics, and consent from the third party. Other possibilities were patients came on holiday and that constrained the agreement problem with the person in charge and the availability of antibiotic in pharmaceutical installation was limited.

Although patients should receive their initial treatment within an hour of presentation to an emergency department, this goal was problematic for many reasons, in both clinical and administrative ways. For example, patients must be properly evaluated with laboratory tests and radiographs to determine neutropenia and to identify a possible source of infection (10). Meisenberg et al. showed the longest delayed treatment were a consequence of the conscious or functional decision to pause the delivery of antibiotics while awaiting transfer to an inpatient unit. This delayed treatment is a result of lack of appreciation for the pathophysiology of infection and potential sepsis (11).

To answer the objectives of this study, a multivariate analysis should be established. Because there was only one variable (adherence to management algorithm) that was significant, multivariate analysis was not done.

\section{CONCLUSIONS}

The mortality rate of febrile neutropenia fever in isolation room during 2008-2012 (20.7\%) in isolation room, Dharmais Hospital-National Cancer Center was decreased compared to year 2000 (22.5\%) and 2002 (38.8\%). The correlation of age, sex, and degree of risk factors did not differ significantly to mortality $(p=0,477$; $0,404 ; 0,324)$. The proportion of mortality rates was higher in case with the third person in charge $(26.8 \%)$ than private $(10 \%)$ although statistically was not significant $(p=0,065)$. From the three types of adherence, only adherence to the management algorhytm of treatment that had a significant effect on mortality rate $(p=0,033)$. A significant parameter in this case is to stop antibiotic/antifungal treatment according to the degree of risk. This was caused by the doctors in charge in isolation room that were consultant of hematology and medical oncology who had the competence, awareness, and understanding of the guideline.

\section{ACKNOWLEDGEMENT}

The authors are grateful to all study team at Dharmais Hospital-National Cancer Center. 


\section{DECLARATIONS}

\section{Ethical approval}

This study used patient's medical record data retrospectively and did not intervene the patient. This study was unrelated to patient safety and did not require informed consent. Ethics in this study includes respecting subject's privacy by not displaying identity, either name or origin address of subjects and using initials as substitution of identity.

\section{Competing of Interest}

The authors declare that they have no competing interests.

\section{REFERENCES}

1. Naurois J, Basso N, Gill MJ, et al. Management of febrile neutropenia: ESMO clinical practice guideline. Annals of Oncology. 2010; 21(5): 252-6.

2. Thursky KA, Worth LJ. Can mortality of cancer patients with fever and neutropenia be improved?. Wolters Kluwer Health, Inc. 2015; 28(6): 505-13.

3. Kyriacou DN, Jovanovic B, Frankfurt O. Timing of initial antibiotic treatment for febrile neutropenia in the emergency department the need for evidence-based guidelines. JNCCN. 2014; 12(11): 1569-73.

4. Penack O, Buchheidt D, Christopeit M, et al. Management of sepsis in neutropenic patients: Guidelines form the infections disease working party of the German Society of Hematology and Medical Oncology (AGIHO). Ann Hematol. 2014; 93: 1083-95.

5. Ranuhardy D. Panduan Tata Laksana Febril Neutropenia/Demam Neutropeni pada Pasien Kanker. Jakarta: Balai Penerbit FKUI; 2006.

6. Ranuhardy D, Sandy D. Febrile Neutropeni pada Pasien Kanker di Rumah Sakit Kanker Dharmais, Evaluasi Keadaan Tahun 2009 (Studi Retropektif). (Unpublished); 2009.

7. Lustberg MB. Management of neutropenia in cancer patients. Clin Adv Hematol Oncol. 2012;10(12):825-6.

8. Djasri, Hanevi. Pemilihan dan Penerapan Pedoman Klinis (Clinical Practice Guideline). Yogyakarta: Bahan Kuliah Audit Klinik MMR; 2011.

9. Kern, Wifried V. Current Epidemiology of Infections in Neutropenic Cancer Patients. In Textbook of Febrile Neutropenia. Kennet VT Rolston, Edward B. Rubenstein (Eds). UK: Martin Dunitz Ltd; 2001. p 57-8.

10. Lyman GH, Rolston KV. How we treat febrile neutropenia in patients receiving cancer chemotherapy. J Oncol Pract. 2010; 6: 149-52.

11. Meisenberg B, Clemons J, Ness J, et al. Improving hospital performance in the treatment of febrile neutropenia. Support Care Cancer. 2015; 23: 371-5. 